\title{
Clinical implications of frequency-force relation
}

\author{
Bjørn Johansen, Adriaan J. Hoelen, Hans Schneider, and Frits L. Meijler \\ From the Department of Cardiology, University Hospital, Utrecht, The Netherlands
}

The best known aspect of the frequencyforce relation is the effect of a short interval on the next following beat: 'postextrasystolic potentiation' (Hoffman, Bindler, and Suckling, 1956). Postextrasystolic potentiation can also be recognized under certain clinical conditions (Brockenbrough, Braunwald, and Morrow, 196I; Durrer, Schuilenburg, and Meijler, 1968), but the compensatory pause, which often follows a premature beat, may confuse the issue, so that the relative contribution of the potentiating mechanism cannot be differentiated from haemodynamic factors. In order to avoid haemodynamic pitfalls, we have attempted a statistical approach, for the study of the frequencyforce relation in the intact organism, making use of patients with atrial fibrillation.

In previous studies we have demonstrated that the ventricular rhythm of patients with atrial fibrillation is random (Meijler, Strackee, van Capelle, and du Perron, 1968; Bootsma, Hoelen, Strackee, and Meijler, 1970). This randomness of the ventricular rhythm indicates the absence of any relation between successive RR intervals and thus allows one to draw conclusions from relationships found between RR intervals and haemodynamic or contractile parameters during atrial fibrillation.

The effect of varying RR intervals on left ventricular contractile behaviour was studied in patients with atrial fibrillation and a StarrEdwards prosthetic mitral valve. With the aid of a phonocardiograph, the closing and opening sounds of the ball valve were recorded. By means of cross-correlation techniques, the relationship between duration of RR interval and timing of the prosthetic mitral valve closing and opening sounds were computed.

The cooperation of the department of cardiovascular surgery has enabled us to study cross-correlation functions between duration of RR interval and aortic blood flow in patients with atrial fibrillation during thoracotomy.

\section{Methods}

In eight patients ranging in age from 26 to 52 years (Table I), with atrial fibrillation and a prosthetic mitral valve, the closing and opening sounds of the valve, together with the EKG of I,000 successive beats, were recorded on magnetic tape.

Figure I presents an example of a typical recording. Next the recorded QRS complexes together with the heart sounds were transformed into rectangular pulses by playback and appropriate filtering and triggering as described in a previous paper (Bootsma et al., 1970). These pulses together with the original signals were written at $50 \mathrm{~mm} / \mathrm{sec}$ on a multichannel paperrecorder. The RR intervals and time relations between $\mathrm{R}$ wave and closing and opening sounds of the valve of at least 250 successive beats were measured from the strips by hand. The intervals between subsequent $\mathbf{R}$ waves and between $\mathbf{R}$ waves and closing sound (RCI) and between closing and opening sounds (mitral valve closure time, VCT) were listed separately. The mitral valve closure time (VCT) represents the duration of the mechanical systole of the left ventricle.

A computer (IBM 7094) processed serial crosscorrelation coefficients between RR intervals and $\mathrm{RCI}$ and between RR intervals and VCT. Also scatter-diagrams between RR interval and $\mathrm{RCI}$ and VCT were plotted.

In three patients (Table 2) with atrial fibrillation, who underwent a thoracotomy for cardiac surgery the EKG, together with aortic blood flow, was recorded on magnetic tape for 5 to 10 min. The flow was measured by means of an electromagnetic blood flowmeter (Nikroton), the probe being placed around the root of the aorta (Reneman, Schneider, Wieberdink, and Brouwer, 1970).

Figure 2 presents a typical recording. Next RR intervals together with the maximum of the first derivative of the flow rate signal $(\max . \mathrm{dF} / \mathrm{dt})$, peak flow velocity, and after integration stroke volume were measured. A good calibration of an electromagnetic blood flowmeter during cardiac surgery is difficult to obtain. Since we were mainly 
TABLE I Distribution of patients with atrial fibrillation and a Starr-Edwards mitral valve by age, sex, diagnosis, and correlation coefficients (CC).

\begin{tabular}{|c|c|c|c|c|c|c|c|}
\hline \multirow[t]{2}{*}{ Patient } & \multirow[t]{2}{*}{$\operatorname{Sex}$} & \multirow{2}{*}{$\begin{array}{l}\text { Age } \\
(y r .)\end{array}$} & \multirow[t]{2}{*}{ Diagnosis } & \multicolumn{2}{|c|}{$R C I$} & \multicolumn{2}{|c|}{$V C T$} \\
\hline & & & & Ist $C C$ & and $C C$ & Ist $C C$ & and $C C$ \\
\hline C.M. & M & 26 & MS, MI, AI & -0.83 & +0.29 & $+0,85$ & +0.07 \\
\hline J.L. & M & $4 I$ & MI & -0.87 & +0.33 & +0.80 & -0.12 \\
\hline D.H. & $\mathrm{M}$ & 48 & MS, MI & -0.86 & +0.34 & +0.83 & $-0 . \mathrm{II}$ \\
\hline C.B. & M & 40 & MS, MI & -0.73 & +0.35 & +0.70 & -0.02 \\
\hline G.S. & $\mathrm{M}$ & 52 & MS, MI & -0.69 & +0.44 & +0.70 & -0.26 \\
\hline F.A. & $\mathrm{M}$ & 34 & MI & -0.91 & +0.23 & +0.83 & +0.05 \\
\hline J.B. & M & 29 & MS, AI & -0.68 & +0.38 & +0.69 & +0.05 \\
\hline A.H. & $\mathrm{F}$ & 38 & MI & $-0.9 I$ & +0.35 & +0.87 & -0.10 \\
\hline
\end{tabular}

$\mathrm{MS}=$ mitral stenosis $. \quad \mathrm{MI}=$ mitral insufficiency. $\quad \mathrm{AI}=$ aortic insufficiency.

interested in beat-to-beat variations, we expressed the aortic flow measurements in arbitrary units. The computer processed serial cross-correlation coefficients between RR intervals and the flow parameters mentioned and plotted scatterdiagrams between RR intervals and the flow parameters.

\section{Results}

I. Effect of RR intervals on timing of closing and opening of valve

Figure 3 presents a diagram of the effect of RR interval changes on RCI and VCT. The measurements are derived from a representative piece of recording. It can be seen that, in general, a short RR interval is followed by a long RCI and a short VCT and a long RR interval is followed by a short RCI and a long VCT. The effect of RR interval on duration of mechanical systole of the left ventricle as presented by duration of mitral valve closure is clearly visible.

Figure 4 presents a scatter-diagram between RR interval and duration of mechanical systole, directly following that interval, in a patient with atrial fibrillation. The high correlation $(0.85)$ between the two parameters should be noted.

Figure 5 presents the relationship between $\mathrm{RR}$ interval and RCI in the same patient. One finds a high negative correlation $(-0.83)$ between preceding RR interval and the interval between $\mathrm{R}$ wave and moment of mitral valve closing sound.

FIG. I Recording of heart sounds in a patient with atrial fibrillation and a Starr-Edwards prosthetic mitral valve, together with a drawing of the valve in the closed and open position. The time between $R$ wave and first heart sound (closing sound) is the RCI (see text). The time between the first heart sound and the mitral valve opening sound, VCT (see text) represents the duration of the mechanical systole of the left ventricle. (This key Figure is reproduced on a small scale in Figs. 4, 5, 6, and 7.)
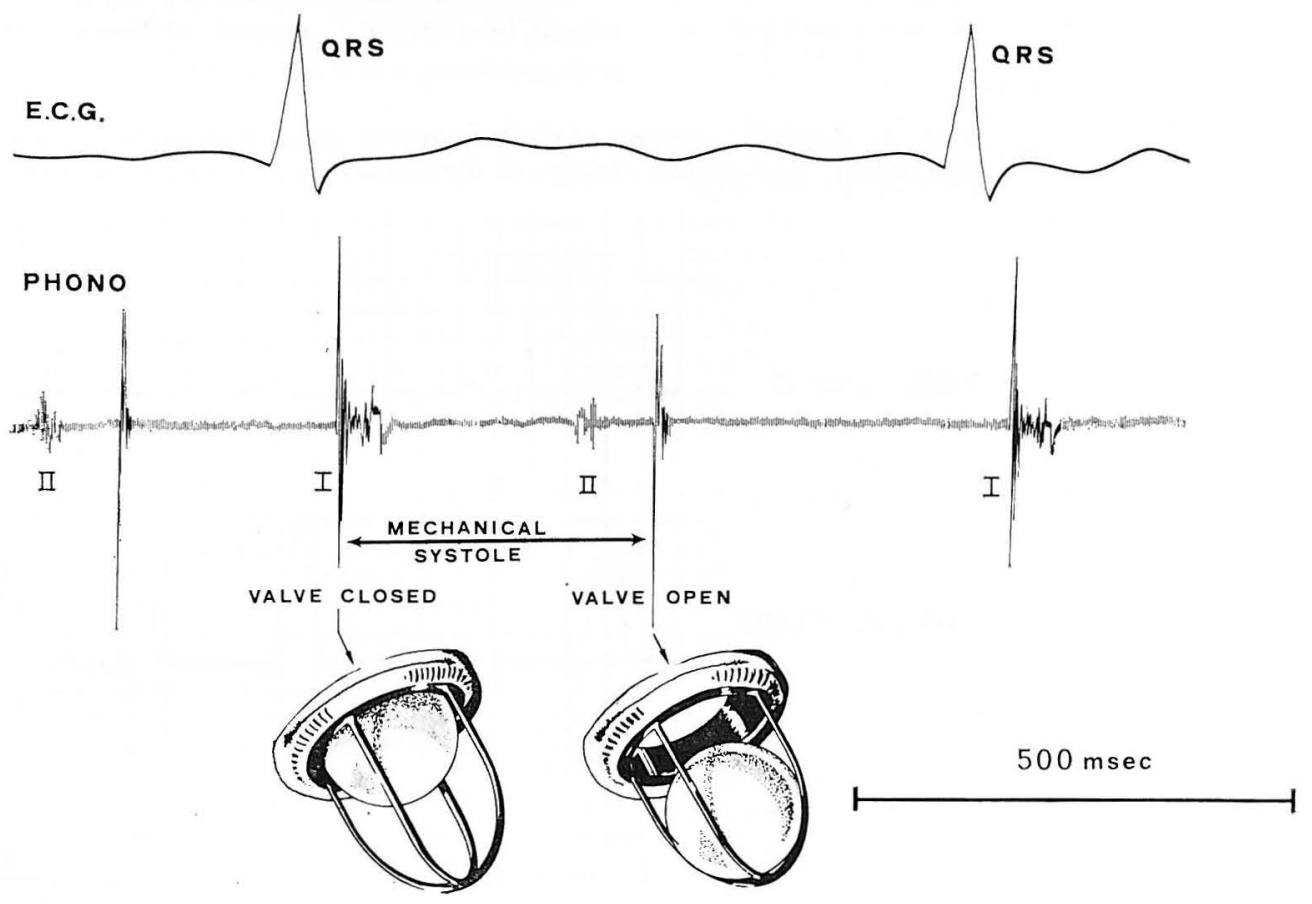
TABLE 2 Distribution of patients with atrial fibrillation and aortic flow recording by age, sex, diagnosis, and correlation coefficients $(C C)$

\begin{tabular}{|c|c|c|c|c|c|c|c|c|c|}
\hline \multirow[t]{2}{*}{ Patient } & \multirow[t]{2}{*}{ Sex } & \multirow{2}{*}{$\begin{array}{l}\text { Age } \\
(y r .)\end{array}$} & \multirow[t]{2}{*}{ Diagnosis } & \multicolumn{2}{|c|}{$S V$} & \multicolumn{2}{|c|}{ Peak flow } & \multicolumn{2}{|c|}{$M a x . d F / d t$} \\
\hline & & & & Ist $C C$ & 2nd $C C$ & Ist $C C$ & 2nd $C C$ & Ist $C C$ & 2nd $C C$ \\
\hline J.H. & $\mathrm{F}$ & 45 & MS & +0.90 & -0.14 & $+0.8 \mathrm{I}$ & -0.20 & +0.79 & -0.37 \\
\hline B.S. & $\mathrm{F}$ & 57 & AS, MS, MI & +0.85 & -0.45 & +0.80 & -0.52 & +0.80 & -0.48 \\
\hline H.B. & $\mathrm{F}$ & 62 & $\mathrm{AS}, \mathrm{MS}, \mathrm{MI}$ & +0.83 & -0.29 & +0.80 & -0.37 & +0.58 & -0.56 \\
\hline
\end{tabular}

$\mathrm{AS}=$ aortic stenosis. $\mathrm{MS}=$ mitral stenosis. $\mathrm{MI}=$ mitral insufficiency. $\mathrm{SV}=$ stroke volume.

Figure 6 shows the serial crosscorrelograms between RR intervals and duration of mechanical systole in five patients with atrial fibrillation and a prosthetic mitral valve. For the sake of clarity the results of only five of the eight patients are shown. In Table 1, the first and the second coefficients of RCI and VCT of all eight patients are given. The first coefficients (the correlation) between RR interval and VCT are all in the order of 0.85 (see also Fig. 4). It should be noted that the second and following coefficients are within their confidence limits of a zero value.

Figure 7 presents the serial crosscorrelograms between RR intervals and RCI of the same five patients as shown in Fig. 6. The first order coefficients are strongly negative (in the order of -0.80 ), while the second coefficients turn out to be positive.
This demonstrates the effect of RR intervals on the next following beats. A long RR interval shortens the period between $R$ wave and mitral valve closing time but at the same time lengthens the RCI of the beat coming thereafter. The opposite is also the case, a short RR interval increases RCI of the first beat and decreases RCI of the second beat.

To summarize: there exists a strong positive correlation between RR interval and duration of mechanical systole and a strong negative correlation between RR interval and $\mathrm{RCI}$ for the beats directly following the RR intervals. At the same time, there is a small positive correlation between RR interval and $\mathrm{RCI}$ of the second following beats (Fig. 7).

\section{Effect of RR intervals on aortic flow}

Figure 8 presents a scatter-diagram between RR interval and stroke volume, directly following that interval in a patient with atrial fibrillation during thoracotomy. The high correlation $(0.85)$ between RR interval and stroke volume should be noted. A high correlation was also found between RR interval and aortic peak flow $(0.80)$ as well as between RR interval and $\mathrm{dF} / \mathrm{dt}(0 \cdot 80)$. The second coefficient was -0.52 for the peak flow and -0.48 for the $\mathrm{dF} / \mathrm{dt}$.

Figure 9 presents the serial cross-correlograms between RR interval and stroke volume in three patients with atrial fibrillation during thoracotomy. The first order coefficients are all in the order of 0.85 . The second coefficients are negative (in the order

FIG. 2 Typical recording of electromagnetic blood flow in the aorta in a patient with atrial fibrillation. Beat-to-beat changes in the blood flow rate signal should be noted.

AORTIC FLOW

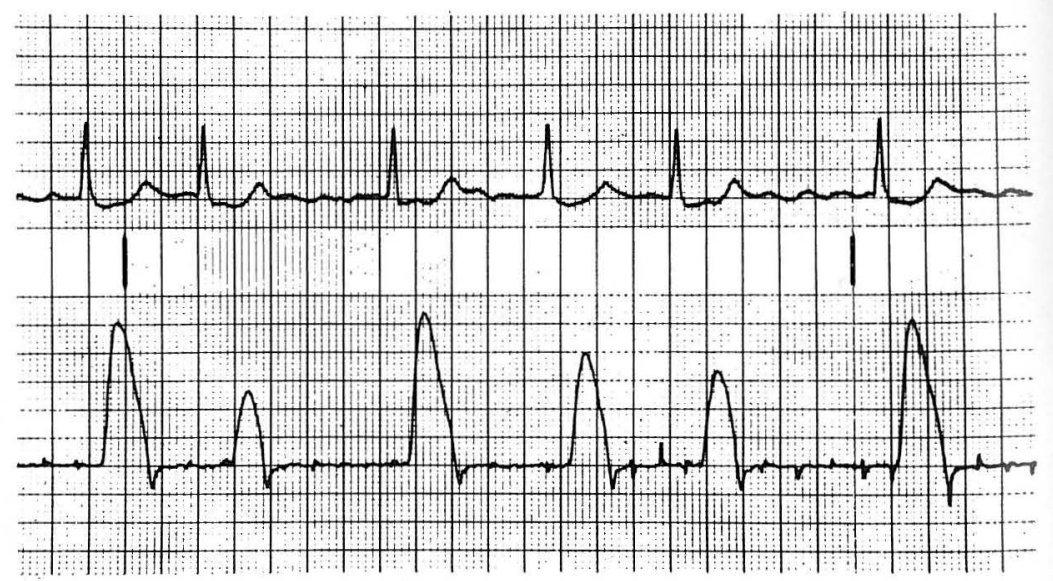




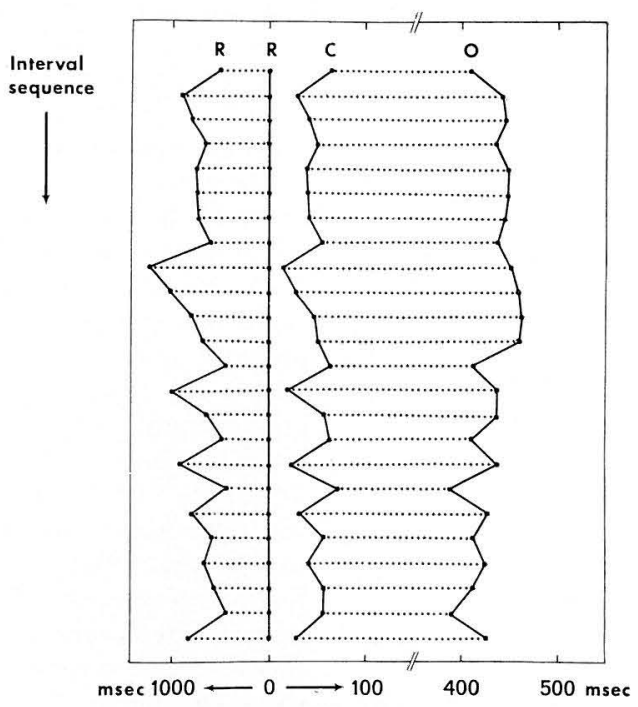

FIG. 3 Diagrammatic representation of variation in $R R$ intervals and time relations of closing and opening of the prosthetic mitral valve. The $R$ wave directly preceding the contraction was taken as the reference. It can be seen that a long $R R$ interval is followed by a short $R C$ interval $(R C I)$ and a long mechanical systole (interval between $C$ and $O$ ), a short $R R$ interval having the opposite effect.

FIG. 4 Scatter-diagram of the correlation between directly preceding $R R$ interval and duration of mechanical systole in a patient with atrial fibrillation and a prosthetic mitral valve.

Duration of

mechanical systole

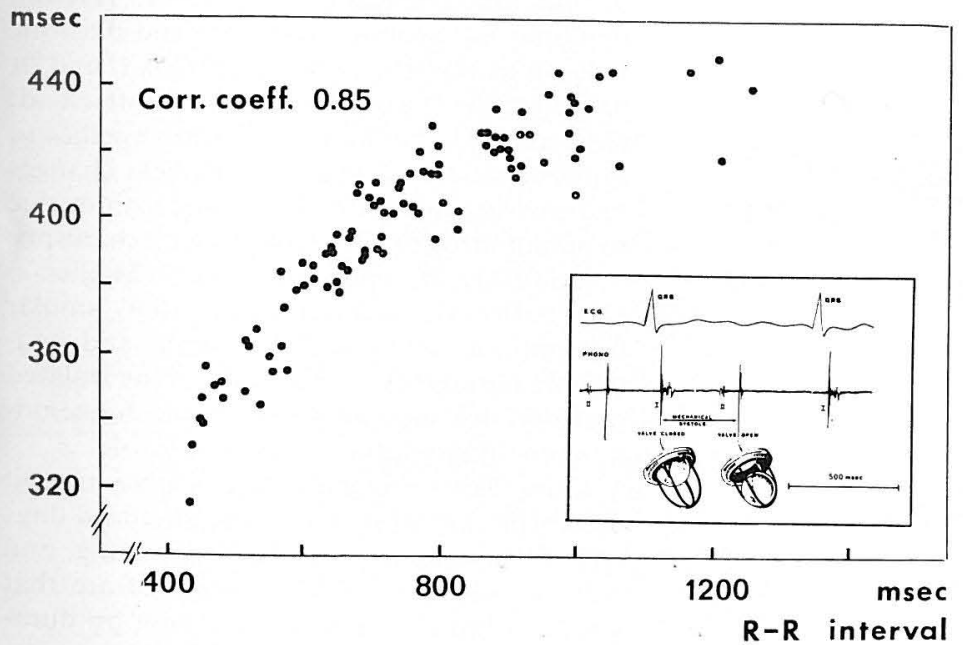

of -0.30 ). This demonstrates the effect of RR interval on a haemodynamic property (in this case stroke volume) of both the beat directly following that RR interval and the second following beat.

Approximately the same cross-correlograms were found (only slightly different quantitative results) between RR interval and max. dF/dt and peak aortic flow (Table 2).

To summarize: there exists a strong positive correlation between the RR interval, the first following stroke volume, and other aortic flow variables and a negative correlation between RR interval and the second following aortic flow variables (stroke volume, max. $\mathrm{dF} / \mathrm{dt}$, and peak aortic flow).

\section{Discussion}

\section{Evaluation of methods}

The assessment of the mechanical events of the left ventricle by atraumatic techniques has recently been reviewed (Kumar and Spodick, 1970). In I968 Beck and Schrire described a method of studying myocardial contractility from phonocardiographically measured time components of ventricular contraction in patients with prosthetic aortic valves. To study the effect of varying RR intervals on some aspects of left ventricular contraction, we used phonocardiographically measured time components in patients with atrial fibrillation and prosthetic mitral valves.

It has been shown that, in certain circumstances, contraction and relaxation of mammalian cardiac muscle are related (Parmley and Sonnenblick, 1969) - a more forceful contraction being followed by a faster relaxation. Preliminary studies in dogs (Eradus and Zimmerman, 1970) have shown that the maximum speed of the ball of a prosthetic mitral valve is higher at the onset than at the end of the ventricular contraction. In atrial fibrillation the force of each ventricular contraction varies, producing a beat-to-beat effect on the speed of the ball valve in either direction and introducing a possible error.

In our laboratory we are currently studying the effect of beat-to-beat changes of the force of ventricular contraction (and relaxation) on the speed of a ball in a prosthetic mitral valve in dogs during random stimulation of the heart.

We have already found that the time it takes for the valve to close does not exceed Io msec. This indicates that the speed of the ball valve movement cannot account solely for the differences in VCT and RCI as shown in Figs. 3, 4, and 5. We therefore feel that timing of ball valve closing and opening 


\section{$\mathrm{R}-\mathrm{C}$ interval}

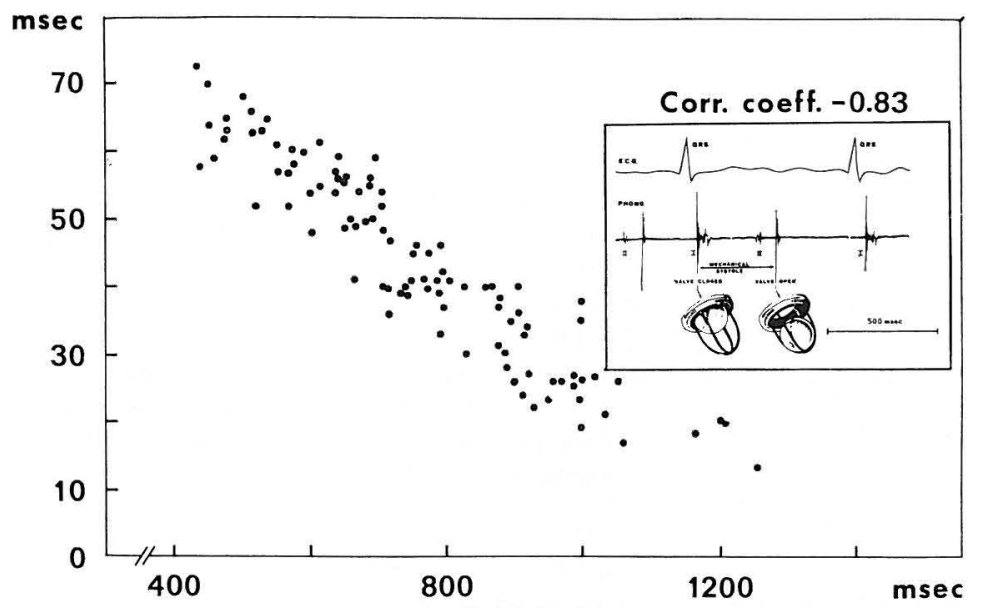

$\mathbf{R}-\mathbf{R}$ interval

FIG. 5 Scatter-diagram of the correlation between the directly preceding $R R$ interval and $R C$ interval in a patient with atrial fibrillation and a prosthetic mitral valve.

FIG. 6 Serial cross-correlograms between $R R$ intervals and duration of mechanical systole in 5 patients with atrial fibrillation and a prosthetic mitral valve.

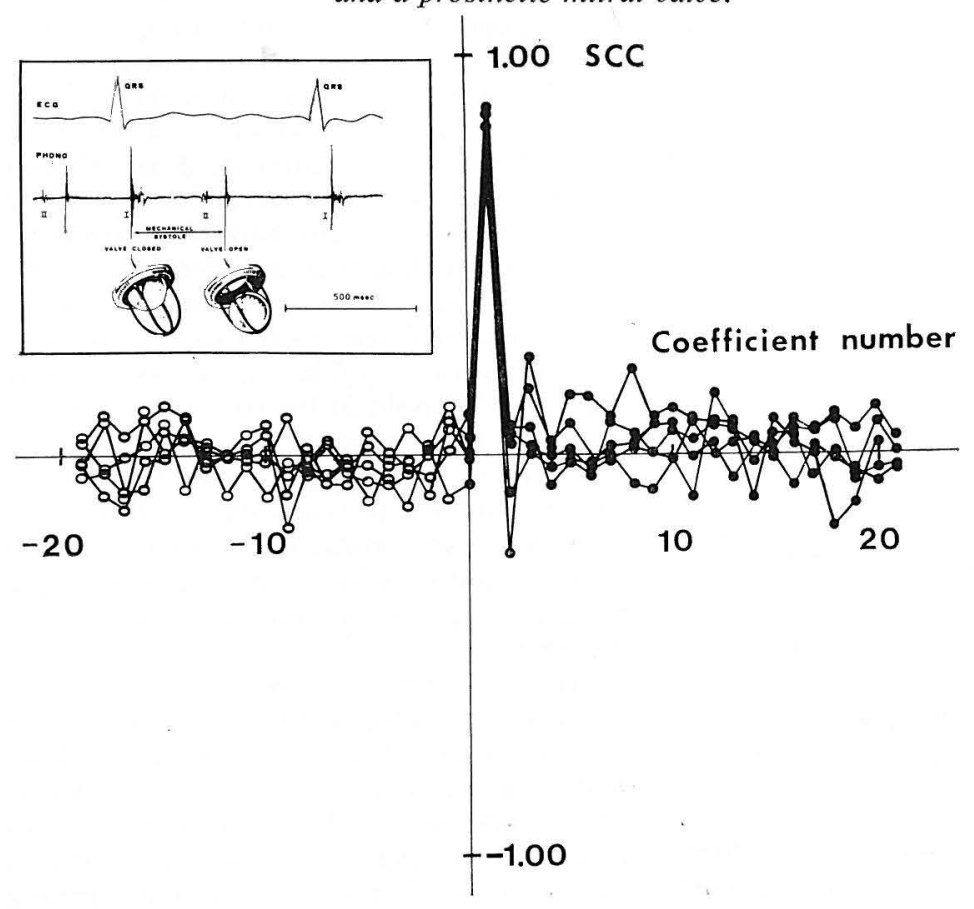

contains important (though as yet not quantifiable) information on left ventricular contractile behaviour. It has the advantage that long lasting measurements can be obtained without injuring or jeopardizing the patient.

The early closure of the valve (early occurrence of the first heart sound) after a long interval need not only be due to a more forceful contraction. It is well known that a mitral ball valve has a slightly stenotic effect causing a pressure gradient between atrium and ventricle. In cases of atrial fibrillation this pressure gradient is variable. After a long R R interval (long diastolic pause), the pressure difference between left atrium and left ventricle may have levelled off, at least be smaller than after a short diastolic pause. The forthcoming ventricular contraction does not have to overcome a quantitative significant pressure difference and an early closure of the valve can occur. In addition, the site of the ball in the cage is not fixed. During long diastoles the ball may float towards the open end of the cage, which actually may contribute to an early closure of the ball valve after long RR intervals.

Although stroke volume is dependent on many contractile and non-contractile influences, it is one of the most relevant parameters of the pump-function of the heart, though peak flow and max. $\mathrm{dF} / \mathrm{dt}$ are probably more relevant to the contractile properties of the myocardium.

\section{Evaluation of results}

A high correlation was found between RR interval and RCI, VCT, and stroke volume of the contraction directly following that RR interval. It is difficult - if at all possible to evaluate the relative contribution of the frequency-force relationship to the magnitude of the first correlation coefficient. Haemodynamic influences, such as end-diastolic volume of the left ventricle (preload) and/or end-diastolic pressure in the aorta (afterload) tend to affect the first correlation coefficient in the same direction as beat-to-beat changes in the contractile state of the myocardium, due to potentiating or depotentiating mechanisms.

However, in a previous paper (Meijler et al., I968) we demonstrated that similar correlations between RR interval and contractile parameters were found in the isolated perfused mammalian heart, in which haemodynamic factors did not play any role.

Using electromagnetic flow probes around the aortic root in intact unanaesthetized dogs with a sinus arrhythmia, Scher, Young, and Kehl (I968) were able to demonstrate that stroke volume is heavily dependent on dura- 


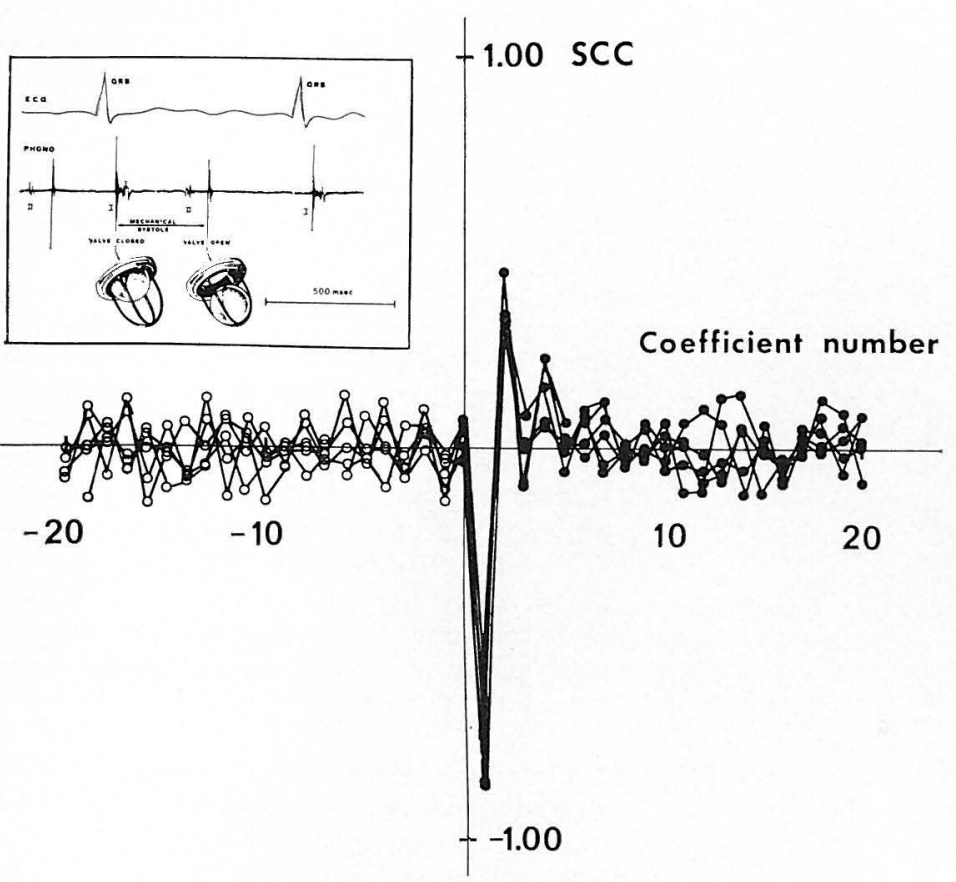

FIG. 7 Serial cross-correlograms between $R R$ intervals and $R C$ interval in 5 patients with atrial fibrillation and a prosthetic mitral valve. The first coefficient is strongly negative. The positivity of the second coefficients should be noted.

FIG. 8 Scatter-diagram of the correlation between the directly preceding $R R$ interval and stroke volume (arbitrary units) in a patient with atrial fibrillation.

\section{Stroke volume}

(arb. units)

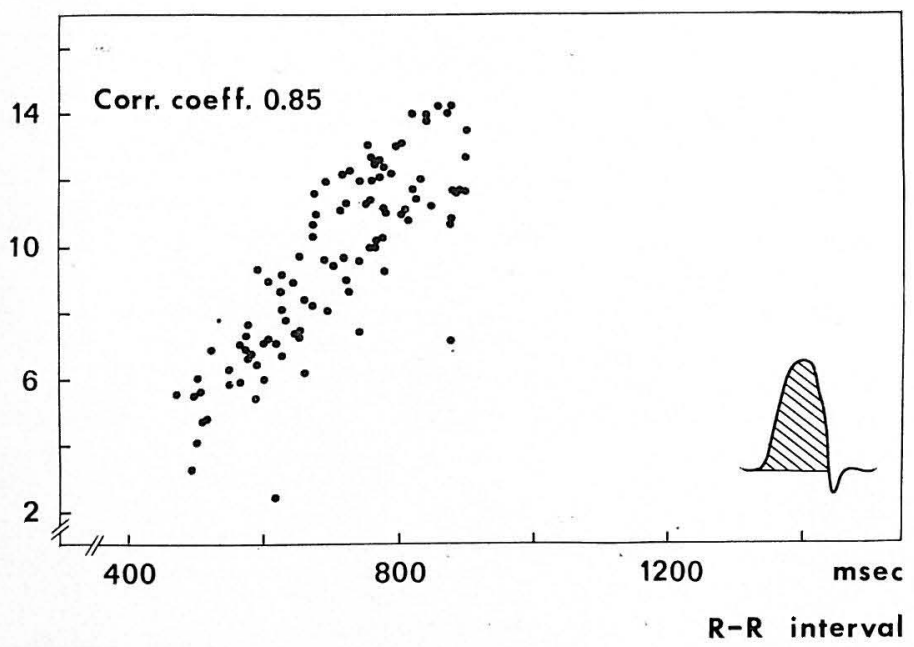

tion of the preceding interval, as well as on filling pressure and arterial pressure. It was not felt to be permitted to make any statement regarding the importance of each variable. In the patients we have studied it was also not possible to assess the relative contribution of each separate regulation mechanism to left ventricular performance. We have therefore focused our attention on the second cross-correlation coefficient (Figs. 6,7 , and 9). This coefficient very probably expresses the influence of the frequency-force relation. It is the only mechanism that can explain why the mitral valve closes earlier after a short pre-preceding cycle or later after a long pre-preceding cycle (positive second correlation coefficient, Fig. 7). A short interval potentiates the second following beat which may give rise to an early mitral valve closure. A long interval depotentiates the second following beat, the contraction becomes weaker, and the mitral valve closure comes relatively later.

In retrospect, it has to be said that in patients with atrial fibrillation the duration of the mechanical systole (VCT) is not a good parameter to detect a frequency-force relation in left ventricular contractile behaviour. An effect of RR interval on VCT of the second following beat was not demonstrable. We know from studies with isolated hearts (Meijler, van den Bogaard, van der Tweel, and Durrer, 1962) that a single short RR interval decreases height and shortens duration of the contraction directly following that $R R$ interval, while a single long RR interval increases height and lengthens duration of the directly following contraction. This can explain the first highly positive serial crosscorrelation coefficient between RR interval and duration of mechanical left ventricular systole (VCT). The second following potentiated beat after the single short interval is large and wide and the depotentiated beat due to a single long interval is small(er) and narrow. From this phenomenon, one would expect a negative second coefficient. However, at a (steady state) high heart rate contractions are large and narrow and at a low rate small and wide (Meijler, 1962). Since during a random rhythm there is a continuing transition between high and low rates, the steady state phenomenon, just described, might counteract the widening (or narrowing) effect of one single beat on VCT and thus explain why the second coefficient does not significantly differ from zero.

Stroke volume, and also the other aortic flow variables, show a negative second crosscorrelation coefficient. A short RR interval 


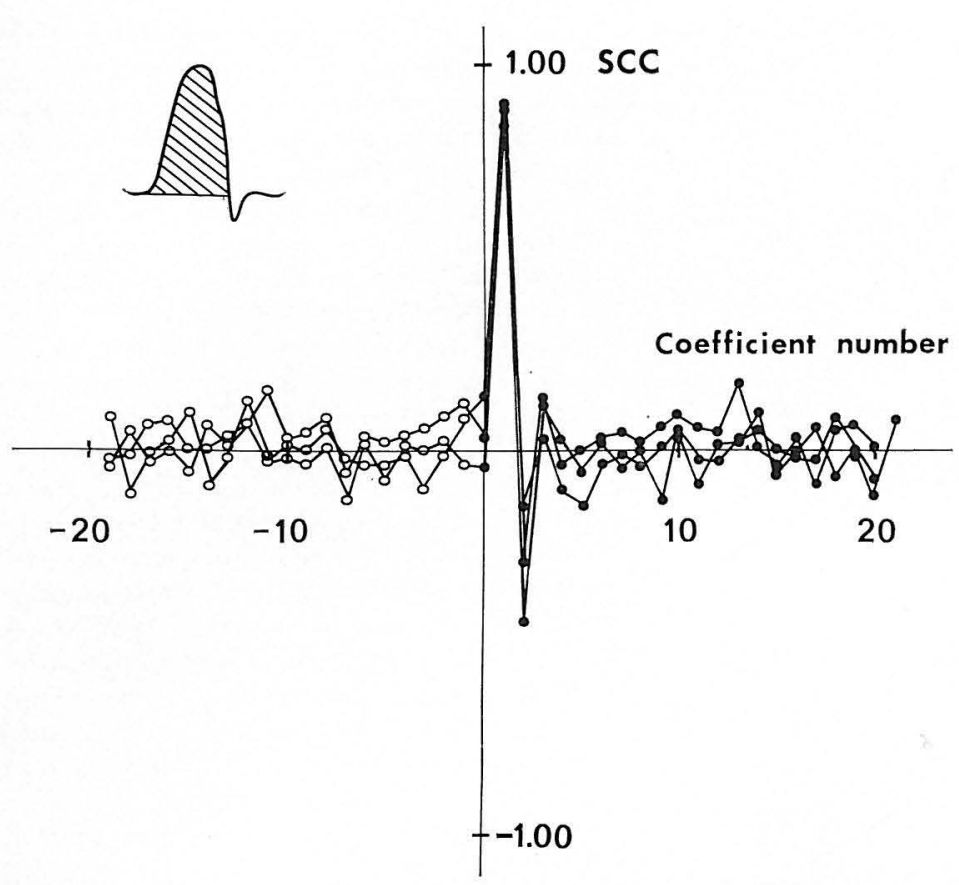

FIG. 9 Serial cross-correlograms between $R R$ intervals and stroke volume in three patients with atrial fibrillation. The first coefficient is strongly positive. The negativity of the second coefficients should be noted.

increases stroke volume of the second following beat, a long RR interval has the opposite effect. This can be explained only by the frequency-force relation. The absolute value of the second coefficient might reflect the relative contribution of pre-preceding interval to stroke volume.

\section{Conclusions}

We feel that these results present qualitative evidence of the beat-to-beat effect of the frequency-force relation in the intact human organism. The regulation of the intact circulation is complicated and depends on a number of factors operating at the same time (Meijler, 1969).

These factors influence each other, which makes it very hard to select and study the effect of one such factor on the regulation of the circulation. A statistical approach making use of random ventricular rhythms in patients with atrial fibrillation seems to enable one to select a single factor such as the frequencyforce relation. Of course more work is needed further to evaluate the effect of frequencyforce relation on other contractile or haemodynamic parameters in the intact unanaesthetized organism.
The absolute value of the second crosscorrelation coefficient of a relevant parameter could be indicative for the contractile state of the myocardium, hopefully enabling the clinician to distinguish heart failure due to abnormal loading from that resulting from depression of myocardial function per se.

\section{Summary}

In order to assess the frequency-force relationship in man, the relation between RR intervals and timing of closing and opening sounds of a prosthetic mitral valve was studied by means of cross-correlation techniques in eight patients with atrial fibrillation.

The relation between $\mathrm{RR}$ intervals and aortic blood flow velocity was also studied with the same techniques in three patients with atrial fibrillation during thoracotomy. Computer facilities were used for the data processing.

Frequency-force relation could be demonstrated in the cross-correlograms between RR interval and the interval between the occurrence of the $R$ wave and the mitral valve closing sound and also in the crosscorrelograms between RR interval and aortic blood flow parameters such as stroke volume.

We thank Professor Nieveen of Groningen and Professor Snellen of Leiden for sending us patients with atrial fibrillation and a prosthetic mitral valve. We also thank Professor Strackee of Amsterdam and Professor Denier van der Gon of Utrecht for their help and criticism.

\section{References}

Beck, W., and Schrire, V., (I968). An attempt at the assessment of myocardial contractility from phonocardiographically measured time components of ventricular contraction in patients with prosthetic aortic valves. Circulation, 38, 489-504.

Bootsma, B. K., Hoelen, A. J., Strackee, J., and Meijler, F. L. (1970). Analysis of RR intervals in patients with atrial fibrillation at rest and during exercise. Circulation, 4I, 783-794.

Brockenbrough, E. C., Braunwald, E., and Morrow, A. G. (I96I). A hemodynamic technic for the detection of hypertrophic subaortic stenosis. Circulation, 28, I 89-194.

Durrer, D., Schuilenburg, R. M., and Meijler, F. L. (1968). Clinical investigation of paired stimulation and postextrasystolic potentiation in Paired Pulse Stimulation of the Heart. Rockefeller University Press.

Eradus, W. J., and Zimmerman, A. N. E. (1970). Het meten van de beweging van de hartklepprothese. Internal Report M 65. Technical High School, Delft.

Hoffman, B. F., Bindler, E., and Suckling, E. E. (1956). Postextrasystolic potentiation of contraction in cardiac muscle. American Journal of Physiology, I85, 95-102. 
Kruta, V. (1937). Sur l'activité rhythmique du muscle cardiaque. Variations de la réponse mécanique en fonction du rhythme. Archives Internationales de Physiologie, 45, 332-357.

Kumar, S., and Spodick, D. H. (1970). Study of the mechanical events of the left ventricle by atraumatic techniques: Comparison of methods of measurement and their significance. American Heart Journal, 80, 40I-4I3.

Meijler, F. L., van den Bogaard, F., van der Tweel, L. H., and Durrer, D. (I962). Postextrasystolic potentiation in the isolated rat heart. American Journal of Physiology, 202, 63 I-635.

Meijler, F. L. (I962). Staircase, rest contractions and potentiation in the isolated rat heart. American Journal of Physiology, 202, 636-640.

Meijler, F. L., Strackee, J., van Capelle, F. J. L. and du Perron, J. C. (I968). Computer analysis of the
RR interval contractility relationship during random stimulation of the isolated heart. Circulation Research, 22, 695-702.

Meijler, F. L. (I969). The role of the heart in the regulation of the circulation. Acta Physiologica et Pharmacologica Neerlandica, 15, 282-287.

Parmley, W. W., and Sonnenblick, E. H. (1969). Relation between mechanics of contraction and relaxation in mammalian cardiac muscle. American Journal of Physiology, 216, 1084-109I.

Reneman, R. S., Schneider, H., Wieberdink, J., and Brouwer, F. A. S. (1970). Elektromagnetische stroomsterktemeting van het bloed. Nederlands Tijdschrift voor Geneeskunde, II4, 1090.

Scher, A. M., Young, A. C., and Kehl, T. H. (1968). The regulation of stroke volume in the resting unanesthetized dog. Computers and Biomedical Research, I, 315. 